\title{
A Review on Microextraction Techniques for Selected Triazole Fungicides Determination in Water and Food Samples
}

\author{
Ane Bordagaray", Esmeralda Millán and Rosa Garcia-Arrona
}

Applied Chemistry Department, Faculty of Chemistry, University of the Basque Country (UPV/EHU), Manuel de Lardizabal 3, 20018 Donostia- San Sebastian, Spain

"Correspondence to:

Ane Bordagaray

Applied Chemistry Department

Faculty of Chemistry, University of the Basque Country (UPV/EHU), Manuel de Lardizabal 3 20018 Donostia- San Sebastián, Spain

E-mail: ane.bordagaray@ehu.eus

Received: June 06, 2016

Accepted: August 04, 2016

Published: August 08, 2016

Citation: Bordagaray A, Millán E, Garcia-Arrona R. 2016. A Review on Microextraction Techniques for Selected Triazole Fungicides Determination in Water and Food Samples. J Food Chem Nanotechnol 2(3): 128-137.

Copyright: (C) 2016 Bordagaray et al. This is an Open Access article distributed under the terms of the Creative Commons Attribution 4.0 International License (CC-BY) (http:// creativecommons.org/licenses/by/4.0/) which permits commercial use, including reproduction, adaptation, and distribution of the article provided the original author and source are credited.

Published by United Scientific Group

\begin{abstract}
Triazole fungicides are systemic fungicides applied to protect crops from fungus infections. Its use must be controlled due to the potential harmful effects in environment and human health. Before determination with a chromatographic system, analyte must be isolated and preconcentrated with an extraction step. This review presents the most used microextraction techniques for those compounds in water and several food matrices, mainly solid phase microextraction (SPME) and liquid phase microextraction (LPME) procedures. The most relevant analytical parameters of some studies from the recent literature are collected and also some advantages and disadvantages comparing SPME and LPME procedures are presented.
\end{abstract}

\section{Keywords}

Triazole fungicides, Microextraction, SPME, LPME, Water, Food samples

\section{Abbreviations}

AALLME: Air-assisted liquid-liquid microextraction; CPE: Cloud point extraction; DLLME: Dispersive liquid-liquid microextraction; GBMNE: Graphene-based magnetic nanoparticles extraction; GC-ECD: Gas chromatography-electron capture detector; GC-FID: Gas chromatographyflame ionization detector; GC-MS: Gas chromatography-mass spectrometry; GC-NPD: Gas chromatography-nitrogen phosphorous detector; GC-ToF-MS: Gas chromatography-time of flight-mass spectrometry; HF-LPME: Hollow fiber liquid phase microextraction; HPLC-DAD: High-performance liquid chromatography-diode array detector; LC-MS/MS: High-performance liquid chromatography-tandem mass spectrometry; HPLC-UV: High-performance liquid chromatography-ultraviolet detector; IL-DLLME: Ionic liquiddispersive liquid-liquid microextraction; LPME: Liquid phase microextraction; MIP: Molecularly imprinted polymer; SFO: Solidification of floating organic drop; SBSE-DLLME: Stir bar sorptive extraction-dispersive liquid-liquid microextraction; SDME: Single drop microextraction; SEV-DLLME: Silylated extraction vessel-dispersive liquid-liquid microextraction; SPME: Solid phase microextraction; UAE: Ultrasound-assisted extraction; USA-IL-LPME: Ultrasound-assisted ionic liquid dispersive liquid phase microextraction; USAEME: Ultrasound-assisted emulsification microextraction; USAEMME: Ultrasound-assisted emulsification magnetic microextraction; UA-SSILDLLME: Ultrasound-assisted dispersive liquid-liquid microextraction based on the solidification of sedimentary ionic liquids; UASO-HLLME: Ultrasoundassisted salting-out homogeneous liquid-liquid microextraction; VA-MSLDME: Vortex-assisted matrix solid-liquid dispersive microextraction 


\section{Introduction}

The big demand of food leads to use different kind of pesticides in order to protect the crops and increase their production to satisfy the needs of the society. Some studies have shown that the use of pesticides can effectively reduce the plant diseases [1] as well as the delay the oxidative process suffered by the plants delaying senescence and increasing the crop yield [2]. The treated plants are taken by the consumers in different forms, such as the vegetables or processed products as wines or beverages. The Triazole compounds are one of the most common groups of pesticides to fight against fungus diseases widely applied to crops. The mode of action of these azole fungicides is the inhibition of ergosterol, an essential component in fungal cell membranes, by influencing the cytochrome P450 enzyme activity [3]. Many studies have been carried out concerning these pesticides effects in animals. Tumorigenic effects [4], endocrine disrupting effects [5] and disturbances in reproductive systems have been shown in rats [6]. Those fungicides can also induce some tumors in mice livers [7]. Besides, the carryover of the analyte can also hazard the environment, such as increasing mortality rates of Daphnia's (tiny crustaceans), affecting also the plant growth and causing anticholigernic and oxidative stress in fishes [8]. Moreover, it has been shown that triazole fungicides can affect the beer making processes producing sluggish and even stuck of fermentation [9].

The following triazoles were selected according to literature: cyproconazole, difenoconazole, diniconazole, epoxiconazole, fluquinconazole, flusilazole, hexaconazole, metconazole, myclobutanil, penconazole, propiconazole, tebuconazole, tetraconazole and triticonazole. The molecular formula, CAS number and structure as well as the log value of $\mathrm{K}_{\mathrm{OW}}$ of the triazoles are shown in the Table 1. Taking into account the pesticide manufacturers, these compounds can remain in the fruit and therefore the established preharvest security period can be up to a month for some cases. Furthermore, the superficial run-off is not able to take out easily the pesticides and some of them, can stay strongly adsorbed to the soils [10].

Because of the potential health risks to consumers, European Union (EU) has published several regulations to establish maximum residue limits (MRLs) for a wide range of pesticides in different food types. First regulation about MRLs was published in 2005 [11], and from that year new regulations have been done and the MRLs have been updated. These limits for triazoles are ranging from 0.01 to $3.00 \mathrm{mg} \mathrm{kg}^{-1}$ depending on the fruit type and the analyte [12].

Thus, it is necessary to use reliable methods to determine the pesticide residues in different matrices. Traditionally, those analysis have been done using liquid-liquid extraction (LLE) or solid-phase extraction (SPE) [13-15]. LLE is based on the equilibrium distribution/partition coefficient between two immiscible liquids. On the other hand, SPE is based on the selective distribution of analytes between the solid packing material and liquid mobile phase $[15,16]$. The main drawbacks of these two techniques are the important amounts of solvents and the laborious procedures involved. The large amounts
Table 1: CAS number, molecular formulas, structures and log value of $\mathrm{K}_{\mathrm{OW}}$ (partition coefficient between $n$-octanol and water) of the triazole compounds considered in this review.

\begin{tabular}{|c|c|c|c|}
\hline $\begin{array}{c}\text { Name } \\
\text { [CAS RN] }\end{array}$ & Formula & Structure & $\log \mathrm{K}_{\text {ow }}$ \\
\hline $\begin{array}{c}\text { Cyproconazole } \\
\text { [94361-06-5] }\end{array}$ & $\mathrm{C}_{15} \mathrm{H}_{18} \mathrm{ClN}_{3} \mathrm{O}$ & & $\begin{array}{c}2.91 \\
(\mathrm{pH} 7)\end{array}$ \\
\hline $\begin{array}{c}\text { Difenoconazole } \\
\text { [119446-68-3] }\end{array}$ & $\mathrm{C}_{19} \mathrm{H}_{17} \mathrm{Cl}_{2} \mathrm{~N}_{3} \mathrm{O}_{3}$ & & $\begin{array}{c}4.20 \\
\left(25^{\circ} \mathrm{C}\right)\end{array}$ \\
\hline $\begin{array}{l}\text { Diniconazole } \\
\text { [70217-36-6] }\end{array}$ & $\mathrm{C}_{15} \mathrm{H}_{17} \mathrm{Cl}_{2} \mathrm{~N}_{3} \mathrm{O}$ & & $\begin{array}{c}4.3 \\
\left(25^{\circ} \mathrm{C}\right)\end{array}$ \\
\hline $\begin{array}{l}\text { Epoxiconazole } \\
\text { [106325-08-0] }\end{array}$ & $\mathrm{C}_{17} \mathrm{H}_{13} \mathrm{ClFN}_{3} \mathrm{O}$ & & $\begin{array}{c}3.44 \\
(\mathrm{pH} 7)\end{array}$ \\
\hline $\begin{array}{c}\text { Fluquinconazole } \\
\text { [136426-54-5] }\end{array}$ & $\mathrm{C}_{16} \mathrm{H}_{8} \mathrm{Cl}_{2} \mathrm{FN}_{5} \mathrm{O}$ & & $\begin{array}{l}3.24 \\
(\mathrm{pH} \\
5.6)\end{array}$ \\
\hline $\begin{array}{c}\text { Flusilazole } \\
\text { [85509-19-9] }\end{array}$ & $\mathrm{C}_{16} \mathrm{H}_{15} \mathrm{~F}_{2} \mathrm{~N}_{3} \mathrm{Si}$ & & $\begin{array}{c}3.74 \\
(\mathrm{pH} 7, \\
\left.25^{\circ} \mathrm{C}\right)\end{array}$ \\
\hline $\begin{array}{l}\text { Hexaconazole } \\
\text { [79983-71-4] }\end{array}$ & $\mathrm{C}_{14} \mathrm{H}_{17} \mathrm{Cl}_{2} \mathrm{~N}_{3} \mathrm{O}$ & & $\begin{array}{c}3.9 \\
\left(20^{\circ} \mathrm{C}\right)\end{array}$ \\
\hline $\begin{array}{l}\text { Metconazole } \\
\text { [125116-23-6] }\end{array}$ & $\mathrm{C}_{17} \mathrm{H}_{22} \mathrm{ClN}_{3} \mathrm{O}$ & & $\begin{array}{c}3.85 \\
\left(25^{\circ} \mathrm{C}\right)\end{array}$ \\
\hline $\begin{array}{l}\text { Myclobutanil } \\
\text { [88671-89-0] }\end{array}$ & $\mathrm{C}_{15} \mathrm{H}_{17} \mathrm{ClN}_{4}$ & & $\begin{array}{c}2.94 \\
(\mathrm{pH} \\
7-8,25 \\
\left.{ }^{\circ} \mathrm{C}\right)\end{array}$ \\
\hline
\end{tabular}




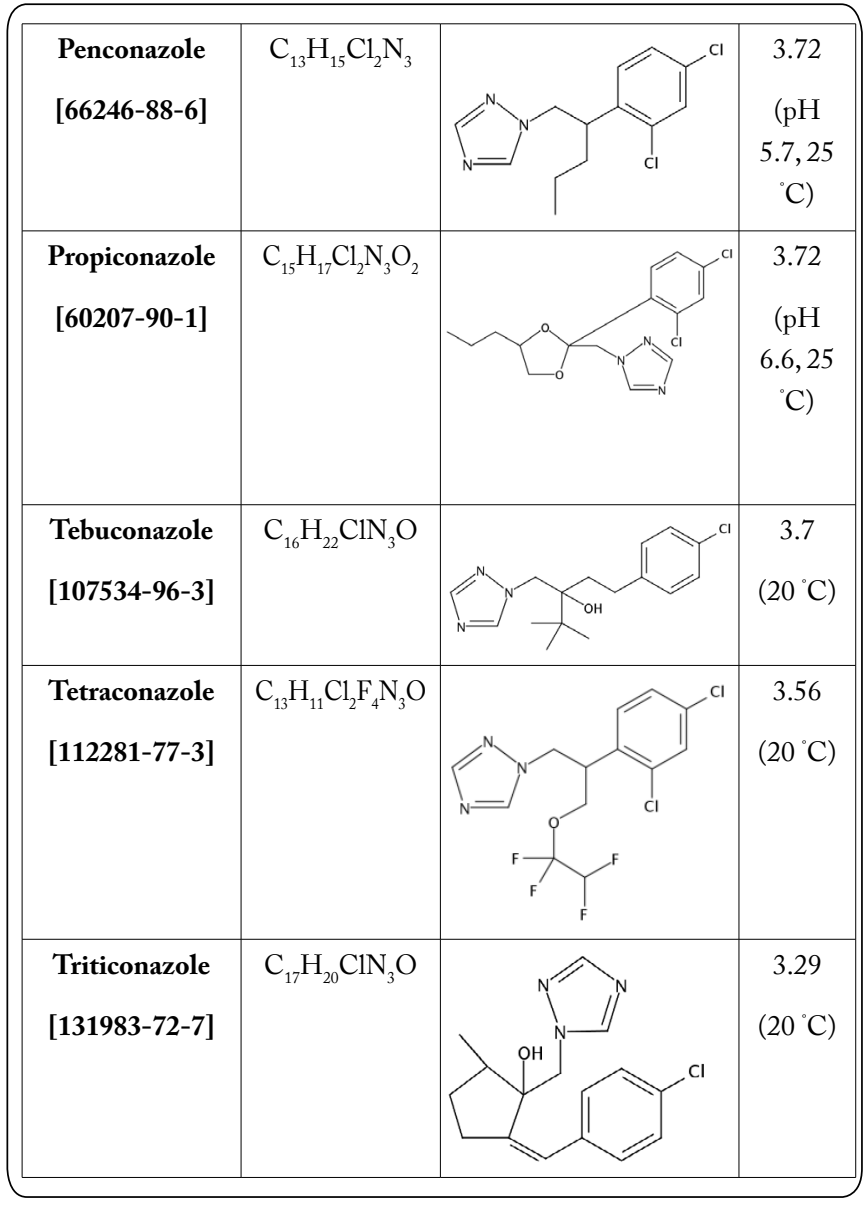

of solvents are against of the green chemistry principle of reducing waste. Moreover, many solvents using in LLE and SPE are difficult to manage after disposal because its toxicity. Regarding procedures, these techniques are performed in many steps that make difficult the automatization and increase error sources due to the loss of analytes.

In 90's began the solid phase microextraction (SPME). This technique avoids the use or uses a limited amount of organic solvents and can be easily automated. Few years later, liquid phase microextraction (LPME) techniques came up to the laboratories giving more versatility to the extraction procedures.

The objective of this work is to provide a summary of the recent developed methods based on several microextraction techniques for the determination of triazole fungicides in water and food samples. Different extractant materials and techniques have been used in those matrices and the obtained precision, accuracy, limits of detection and enrichment factors show wide ranges. Some advantages and drawbacks of SPME and LPME are indicated, as well as the future perspectives.

\section{Analytical microextraction procedures for triazole determination}

In the past years considerable efforts have been made in order to develop new sample preparation techniques that save time and require tiny amounts of hazardous organic solvents. Those microextraction techniques, mainly SPME and LPME, have in common the microliters scale volume of the extractant phase [17].
Solid phase microextraction (SPME) is based on the partition of analytes between the sample phase and a solid extracting phase. SPME consist on a coated polymeric fiber which is exposed to a sample in order to extract the analytes [18]. The fibers can be exposed in three different operation modes: immersion (DI), headspace (HS) or membraneprotected approach [19]. Different variables affect the SPME extraction process, among them: type of coating, extraction time, extraction temperature, salt addition, $\mathrm{pH}$, agitation, sample volume and headspace volume [20-25]. There are some commercially available fibers with different coating and thickness. Polyacrylate (PA), Polydimethylsiloxane (PDMS), and Divinylbenzene (DVB) sorbent materials and its combinations are the most used materials.

After the extraction, GC and HPLC equipment's are mainly used for desorption [26, 27]. In GC, desorption occurs in the injector equipped with a suitable liner where the analytes are thermally desorbed. The maximum allowed temperatures of coatings have to be considered in order to avoid fiber damage. In HPLC, desorption is made in a desorption chamber linked to an injector and the desorption can be performed in two different modes: the static and the dynamic modes [23, 28].

Liquid phase microextraction (LPME) introduces the idea of miniaturizing the classical LLE in a water-immiscible organic droplet [29]. Basically, the droplet is placed directly in the sample or in its headspace and later the droplet is collected with a variety of techniques. Liquid phase microextraction is gaining acceptance in pesticide residue analysis because its different protocols can be adjusted to different aims [30]. LPME is also based on equilibrium between the donor and acceptor phase. The extracted amount in the organic droplet is proportional to the initial concentration. Although the extraction depends on the volume of sample and the organic drop, the partition coefficients remain constant during all the process.

Enrichment factor (EF) can be defined as the ratio of the equilibrium concentration of analyte in the organic phase $\left(\mathrm{C}_{\mathrm{d}}^{\mathrm{eq}}\right)$ to the original concentration $\left(\mathrm{C}_{0}\right)$ of the analyte in the sample [31, 32]. A high enrichment factor indicates good extraction efficiency that helps to improve method validation parameters, such as limit of detection.

$\mathrm{EF}=\frac{\mathrm{C}^{\mathrm{eq}}}{\mathrm{C}_{0}}$

As in the SPME technique there are several variables that need to be taken into account for a successful extraction using LPME techniques [33, 34]. The principal variable to decide is the extractant material $[34,35]$, it must have high affinity with the target analytes, be immiscible with water, be stable enough over the extraction time and it also need to have good chromatographic behavior. The used volume of the droplet also needs to be optimized, because EFs are favored with little volumes [36], but they might be difficult to handle if the droplet is not big enough. As in SPME case, extraction time, temperature and ionic strength also need to be considered, because different extraction efficiency is obtained changing those variables $[34,36]$. The mass transfer can be favored with 
agitation or ultrasonication, both methods help in the sample homogenization increasing the contact surface.

Several papers concerning triazole determination with microextraction techniques have been published. In these studies, water samples, fruit and juice samples, wine, milk, honey and oils have been analyzed. Some of the most used triazole analytes were selected to build the Table 2: cyproconazole (CP), difenconazole (DF), diniconazole (D), epoxiconazole (EPX), fluquinconazole (FQ), flusilazole (FS), hexaconazole (HX), metconazole (MT), myclobutanil (M), penconazole $(\mathrm{PN})$, propiconazole (PR), tebuconazole (TB), tetraconazole (TT) and triticonazole (TRT). The linear range, limits of detection, relative standard deviations (RSD, \%), enrichment factors (EF) and recovery values obtained with different methods are included in Table 2 [37-65].

As it can be seen in the table, five studies considered SPME methods [37-41] where the extractant material was directly immersed in the liquid sample. Headspace mode has not been used due to the low volatility of the triazole compounds. Fibers in immersion mode are more subjected to damage, since solution salt content and other sample compounds can modify the structure of the extractant leading to the breaking of the coating when is not carefully managed [24, 28, 66, 67]. This could be the reason of high reproducibility values for some cases (expressed in Relative Standard Deviation \%) as for example $22.1 \%$ for TB when MIP is used [38].

Highest LOD was obtained for TB when PDMS/DVB is used [41]. Although extraction step is crucial for LOD determination, chromatographic detectors are also important. The reason could be that ECD has low sensitivity for TB. $\mathrm{ECD}$ is a selective detector and thus, not all the compounds can give a good signal.

Farajzadeh et al. proposed a combination of a stir bar sorptive extraction (SBSE) method with a dispersive liquid microextraction to extract analytes from the stir bar coated with octadecylsilane (ODS) [42]. The main advantage of this technique is that allows different coatings that can be design for specific purposes. Hence, it avoids some SPME problems such as fiber fragility or limitation with solvents, and allows better RSD results than SPME (2.9-11.6\%) as well as wider linear ranges $\left(10-50000 \mu \mathrm{g} \mathrm{L} \mathrm{L}^{-1}\right)$.

There are several classifications for liquid microextraction techniques [35, 68-75] and many of those procedures are included in Table 2 [43-65]. Liquid microextraction techniques started with the Single drop microextraction (SDME). This method uses a little amount of the organic solvent $(1-3 \mu \mathrm{L})$ and it is exposed to the sample (DI or HS) at the tip of a micro syringe. After the exposure time, the droplet is collected to further determination. A variation of the simplest method has been developed by Farajzadeh et al. [43], called dynamic single drop microextraction (DSDME). In this case, the droplet is directly placed in the liquid in a narrow bore tube. The tube is reversed upside down several times to extract the analytes and then the droplet is collected by a capillary tube. For all the analytes excellent reproducibility values (2.9$4.5 \%)$ and a wide linear range $\left(10-100000 \mu \mathrm{g} \mathrm{L} \mathrm{L}^{-1}\right)$ has been obtained. Nevertheless high LODs were obtained for both difenconazole isomers (102 and $112 \mu \mathrm{g} \mathrm{\textrm {L } ^ { - 1 }}$ respectively).

Low volatility compounds, such as triazoles, remain mainly in the aqueous phase and not in the headspace. Their extractions are favored with a wide contact between the aqueous phase and the extractant. In dispersive liquid-liquid microextraction (DLLME), the organic droplet is dispersed in the aqueous phase forming a cloudy solution. As a result, an increase of the contact surface area occurs making the extraction more efficient. This dispersion can be made with the help of other solvent (called the dispersive solvent) and with agitation. Afterwards a centrifugation is needed in order to recollect the organic phase into a one droplet again.

Nine studies for triazoles included in Table 2 chose DLLME as the extraction procedure [44-52]. Among different available extractants, the selected for these studies are: hexanol/ hexane mixtures, a chloroform/monochlorobenzene mixture, 1,2-dibromoehtane, chloroform, trimethylchlorosilane, acetonitrile, 1- dodecanol and the ionic liquid [ $\mathrm{C}_{6} \mathrm{MIM}$ ] $\left[\mathrm{PF}_{6}\right]$. Ionic liquids, also known as molten salts, are gaining acceptance in different microextraction procedures. Extraction in those cases is almost immediate and the sample is lead to centrifugation to recollect the droplet. Depending on the used extractant and its density, some of the extractant were collected from the bottom of the used vial directly with a syringe or using the procedure of solidification of floating organic drop (SFO) $[45,48,50-52]$.

Good analytical parameters are obtained in all the studies when DLLME is used. Obtained RSD values are between $0.9-7.25 \%$ except in one of the methods [44], where the maximum RSD value is $11 \%$. Recovery values are good for almost all the cases, but in complex matrices, such as cow milk [50] low recovery values were obtained. The reason may rely on the difficulty to recover the whole liquid extractant in a droplet again. A loss of extractant and hence the analyte can occur in those cases, leading to worse recovery values. The dilution of the samples can partially avoid this problem; but then the analyte amount is also diluted, and as a consequence, analytes may not be detected.

High enrichment factors were obtained in one of the works [49], ranging from 482 to 2738 . In this procedure after analytes were attached to a silylated vessel, the extraction was performed with a methanol and chloroform mixture. Thus, it can be considered as a double extraction procedure and that could be the reason of the high enrichment factors.

Another way to form the cloudy solutions is using ultrasonication [76]. In case of ultrasound-assisted emulsification microextraction (USAEME) no dispersive solvent is needed.The use of US in liquid-liquid microextraction helps in the mass transfer between phases, and also in the formation of the emulsion with tiny droplets of organic phase that increase the contact area. The dispersed phase can be easily collected in one droplet using centrifugation, this procedure can be performed in a few minutes accelerating the separation of the organic and aqueous phase [56, 77-84]. Table 2 shows some of the US extraction procedures for triazole fungicides [53-57]. Ultrasound can be efficient as any dispersive solvent and generally similar results to DLLME are obtained 
Table 2: Analytical characteristics of the triazole determination using microextraction methods.

\begin{tabular}{|c|c|c|c|c|c|c|c|c|c|}
\hline Method $^{a}$ & Extractant material & Matrix & Analytes $^{b}$ & $\begin{array}{l}\text { Linear } \\
\text { range }(\mu \mathrm{g} \\
\left.\mathrm{L}^{-1}\right)\end{array}$ & $\begin{array}{l}\operatorname{LOD}^{c} \\
\left(\mu g L^{-1}\right)\end{array}$ & $\begin{array}{l}\mathrm{RSD}^{\mathrm{d}} \\
(\%)\end{array}$ & $\mathbf{E F}^{\mathrm{e}}$ & $\begin{array}{l}\text { Recovery } \\
(\%)\end{array}$ & Reference \\
\hline $\begin{array}{l}\text { SPME-GC/ } \\
\text { MS }\end{array}$ & $\begin{array}{l}\text { Trimethylsilyl-modified } \\
\text { Nafion/ SBA-15 } \\
\text { nanocomposite }\end{array}$ & Water & $\begin{array}{l}\text { PN-HX-D- } \\
\text { TB-TRT-DF }\end{array}$ & $0.1-2000$ & $0.01-0.09^{1}$ & $4.3-14.1$ & - & - & {$[37]$} \\
\hline $\begin{array}{l}\text { SPME-GC/ } \\
\text { MS }\end{array}$ & MIP & Grape juice & TB-MT & $100-2000$ & $30^{1}$ & $2.9-22.1$ & - & - & {$[38]$} \\
\hline $\begin{array}{l}\text { SPME- } \\
\text { HPLC/DAD }\end{array}$ & $\begin{array}{l}\text { Polydimtehylsiloxane/ } \\
\text { Divinylbenzene (PDMS/ } \\
\text { DVB) }\end{array}$ & $\begin{array}{l}\text { Water, fruit } \\
\text { samples }\end{array}$ & $\begin{array}{l}\text { D-M-FQ-FS- } \\
\text { TB-TT }\end{array}$ & $5.5-50.4$ & $1.5-5.9^{2}$ & $2.8-13.1$ & - & $94.5-123.4$ & [39] \\
\hline $\begin{array}{l}\text { SPME-GC/ } \\
\text { ToF/MS }\end{array}$ & PDMS/DVB & $\begin{array}{l}\text { Grape } \\
\text { Strawberries }\end{array}$ & $\begin{array}{l}\text { D-CP-M-FS- } \\
\text { HX-PN-PR- } \\
\text { TB }\end{array}$ & $0.25-1000$ & $0.25-5^{3}$ & $1.7-14.6$ & - & $84-117$ & {$[40]$} \\
\hline $\begin{array}{l}\text { SPME-GC/ } \\
\text { ECD }\end{array}$ & PDMS/DVB & $\begin{array}{l}\text { Grape and } \\
\text { apple juices }\end{array}$ & D-M-TT-TB & $0.4-2560$ & $0.2-162^{2}$ & $3.3-18.0$ & - & $93.6-112.1$ & {$[41]$} \\
\hline $\begin{array}{l}\text { SBSE- } \\
\text { DLLME- } \\
\text { GC/FID }\end{array}$ & $\begin{array}{l}\text { Octadecylsilane (ODS) } \\
/ 1,1,2,2 \text {-tetrachloroethane }\end{array}$ & $\begin{array}{l}\text { Water } \\
\text { Juices }\end{array}$ & $\begin{array}{l}\text { D-DF-HX- } \\
\text { PN-TB-TRT }\end{array}$ & $10-50000$ & $0.5-24.0^{1}$ & $2.9-11.6$ & $282-1792$ & $71-116$ & {$[42]$} \\
\hline $\begin{array}{l}\text { DSDME- } \\
\text { GC/FID }\end{array}$ & $\begin{array}{l}\mathrm{n} \text {-hexanol: } \mathrm{n} \text {-hexane }(50: 50 \\
\mathrm{v} / \mathrm{v})\end{array}$ & $\begin{array}{l}\text { Water } \\
\text { Grape juice }\end{array}$ & $\begin{array}{l}\text { DF-HX-PN- } \\
\text { TB-TRT }\end{array}$ & $10-100000$ & $2-112^{1}$ & $2.9-4.5$ & $141-214$ & $71-106$ & {$[43]$} \\
\hline $\begin{array}{l}\text { DLLME- } \\
\text { LC/MS/MS }\end{array}$ & $\begin{array}{l}\text { Chloroform/ } \\
\text { monochlorobenzene }\end{array}$ & $\begin{array}{l}\text { Mineral } \\
\text { water }\end{array}$ & CP-TB-EPX & $0.005-0.3$ & $0.005-0.01^{3}$ & $1-11$ & - & $92-120$ & {$[44]$} \\
\hline $\begin{array}{l}\text { DLLME- } \\
\text { GC/NPD }\end{array}$ & $\begin{array}{l}\text { 1,2-dibromoethane }(1,2- \\
\text { DBE) }\end{array}$ & Honey & $\begin{array}{l}\text { D-DF-HX- } \\
\text { PN-TB }\end{array}$ & $0.45-30$ & $0.15-0.70^{1}$ & $3-6$ & 1943-1994 & $97-100$ & {$[45]$} \\
\hline $\begin{array}{l}\text { DLLME- } \\
\text { HPLC/DAD }\end{array}$ & Chloroform & Water & HX-PN-TB & $30-1500$ & $8.6-29.0^{1}$ & $0.9-2.3$ & - & $88-104$ & {$[46]$} \\
\hline $\begin{array}{l}\text { DLLME- } \\
\text { GC/FID/MS }\end{array}$ & $\begin{array}{l}\text { n-hexanol:n-hexane } \\
(75: 25, \mathrm{v} / \mathrm{v})\end{array}$ & Water & $\begin{array}{l}\text { D-HX-PN- } \\
\text { TB-TRT }\end{array}$ & $2-5000$ & $0.3-5.0^{1}$ & $2-12$ & $263-380$ & $74-99$ & {$[47]$} \\
\hline $\begin{array}{l}\text { DLLME- } \\
\text { HPLC/UV }\end{array}$ & Chloroform & Water & TB & $2.0-100$ & $1.2^{1}$ & $2.8-5.3$ & 83 & $90.6-105.3$ & {$[48]$} \\
\hline $\begin{array}{l}\text { SEV- } \\
\text { DLLME- } \\
\text { GC/FID }\end{array}$ & $\begin{array}{l}\text { Trimethylchlorosilane } \\
\text { (TMCS) }\end{array}$ & $\begin{array}{l}\text { Water } \\
\text { Juices }\end{array}$ & $\begin{array}{l}\text { D-DF-HX- } \\
\text { PN-TB-TRT }\end{array}$ & $0.5-20000$ & $0.09-1.04^{1}$ & $2.51-7.25$ & $482-2738$ & $86-103$ & [49] \\
\hline $\begin{array}{l}\text { DLLME- } \\
\text { GC-FID/MS }\end{array}$ & Acetonitrile & Cow milk & $\begin{array}{l}\text { DF-HX-PN- } \\
\text { TB-TRT- }\end{array}$ & $20-80000$ & $2-58^{1}$ & $3.6-6.0$ & $156-435$ & $45-96$ & {$[50]$} \\
\hline $\begin{array}{l}\text { DLLME- } \\
\text { SFO-HPLC/ } \\
\text { DAD }\end{array}$ & 1-dodecanol & Water & M-HX-TB & $0.5-200$ & $0.06-0.1^{1}$ & $4.3-5.7$ & $190-450$ & $86-110$ & {$[51]$} \\
\hline $\begin{array}{l}\text { IL-DLLME- } \\
\text { HPLC/DAD }\end{array}$ & $\begin{array}{l}\text { 1-hexyl-3- } \\
\text { methylimidazolium } \\
\text { hexafluorophosphate } \\
\left(\left[\mathrm{C}_{6} \mathrm{MIM}\right]\left[\mathrm{PF}_{6}\right]\right)\end{array}$ & $\begin{array}{l}\text { Banana } \\
\text { extract }\end{array}$ & TB & $122-6830$ & $3.9^{1}$ & $2.5-5.0$ & - & 93-98 & {$[52]$} \\
\hline $\begin{array}{l}\text { UA-SSIL- } \\
\text { DLLME- } \\
\text { HPLC/UVD }\end{array}$ & $\begin{array}{l}\text { Tributyloctylphosphonium/ } \\
\text { tributyldodecylphosphonium } \\
\left.\left(\left[\mathrm{P}_{4448}\right]\left[\mathrm{PF}_{6}\right]\right)\right)\end{array}$ & $\begin{array}{l}\text { Water } \\
\text { Juices }\end{array}$ & EPX-TB-HX & $5-500$ & $1.10-1.38^{1}$ & $3.4-5.9$ & $94-101$ & $75.4-108.6$ & {$[53]$} \\
\hline $\begin{array}{l}\text { UASO- } \\
\text { HLLME- } \\
\text { GC/MS }\end{array}$ & Acetonitrile, salt & Water & $\begin{array}{l}\text { EPX-DF-M- } \\
\text { TB }\end{array}$ & $10-200$ & $0.8-14.4^{1}$ & $4.0-6.1$ & $120-190$ & $97-115$ & {$[54]$} \\
\hline $\begin{array}{l}\text { USAEME- } \\
\text { SFO-HPLC/ } \\
\text { DAD }\end{array}$ & 1-undecanol & $\begin{array}{l}\text { Water, grape } \\
\text { and apple } \\
\text { samples }\end{array}$ & $\begin{array}{l}\text { D-M-FQ-FS- } \\
\text { TB-TT }\end{array}$ & $20-890$ & $10.9-17.2^{2}$ & $1.9-10.6$ & $226-255$ & $82-112$ & {$[55]$} \\
\hline
\end{tabular}




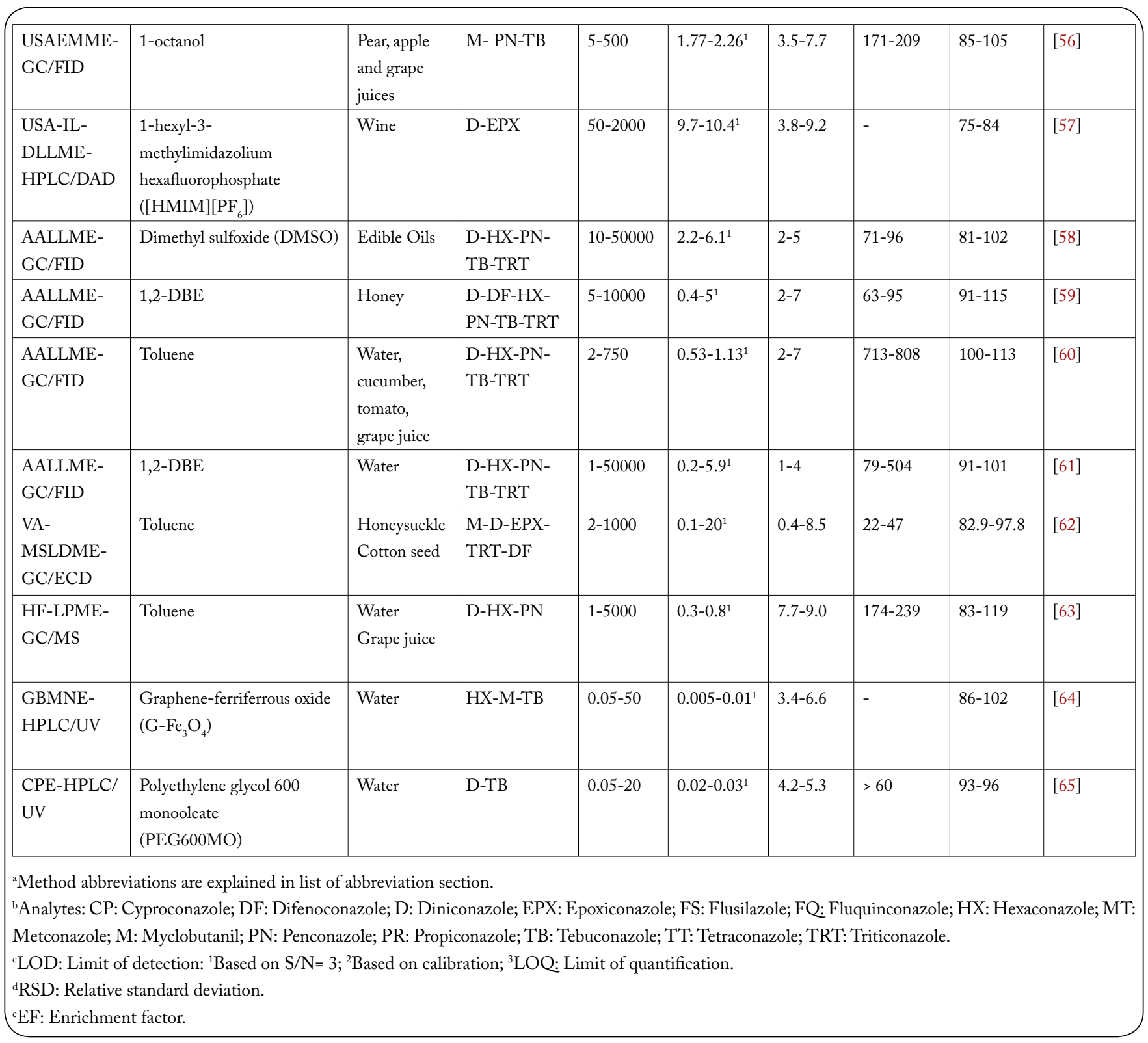

regarding reproducibilities, recoveries and most of the LODs. As in DLLME, in some works an ionic liquid as the extractant solvent has been used $[53,57]$.

Another way to produce a disperse solution is the airassisted liquid-liquid microextraction (AALLME). In this case the dispersion is made by introducing air repeatedly sucking the sample-extractant mixture with a syringe until the solution becomes turbid. Very good RSD values were obtained in the works that used this technique (1-7\%) as well as good recovery values (81-113\%) [58-61].

Apart from the mentioned procedures, there are other studies for triazole fungicides determination that uses vortexassisted matrix-solid liquid dispersive microextraction (VAMSLDME) [62], hollow-fiber liquid phase microextraction (HF-LPME) [63], graphene-based magnetic nanoparticles extraction (GBMNE) [64] or cloud-point extraction (CPE) [65]. In the first one a vortex was used to form the dispersed phase but also was included a primary secondary amine (PSA) as a cleanup adsorbent to eliminate sample interferences.
Although good analytical parameters were obtained in general, poor enrichment factors were achieved (22-47) for the selected triazoles.

In HF-LPME, a porous hollow fiber is used containing the organic phase. Then, the hollow-fiber is introduced to the sample for the extraction and retracted after the exposure time. Similar analytical characteristics were obtained comparing with DLLME, with LODs between 0.3 to $0.8 \mu \mathrm{g} \mathrm{L} \mathrm{L}^{-1}$.

GBMNE is the method in Table 2 with the lowest LODs in the table $\left(0.005-0.01 \mu \mathrm{g} \mathrm{L}^{-1}\right)$. Bolzan et al. [44] also obtained same order LODs, but in that case the used detector is a tandem mass spectrometer, which is much more sensitive than the UV used in GBMNE procedure. The method is based in magnetic nanoparticles added to the sample where the analytes are extracted and finally desorbed with acetone.

The last method, CPE, consists on forming a cloudy solution with a polyethylene glycol surfactant. The function of the surfactant is to preconcentrate the analytes and then, the 
analytes with the surfactant are separated from the aqueous phase with centrifugation. The analytes are injected to the HPLC system together with the surfactant. Low LODs were obtained (0.02-0.03 $\left.\mu \mathrm{g} \mathrm{L}^{-1}\right)$ and good reproducibility values (4.2-5.3\%), but the studied linear range was quite limited (0.05-20 $\left.\mu \mathrm{g} \mathrm{L} \mathrm{L}^{-1}\right)$.

\section{Advantages and disadvantages of SPME and LPME}

Comparing LPME and SPME and its advantages and disadvantages, it can be said that LPME can offer more versatility than SPME. Different LPME approaches give the advantage of adjusting each situation depending on the matrix type, analytes and its properties. For the specific case of triazole fungicides, where the analytes are not volatile, increasing the surface contact area helps the mass transfer, facilitating the extraction and thus, reducing time. That is why the chosen method in most cases is a technique where the extractant is dispersed (DLLME, US-LPME or AALME). However, it is harder to automatize the whole system when LPME procedures are used because the procedure consist on various steps.

The main advantage of using a liquid extractant is that for every analysis a new droplet is used. This fact is reflected in reproducibility of the assays. When SPME is used, especially in DI mode, the extraction is affected by the extraction numbers performed with a single fiber and this leads to worse reproducibility values. In addition, the fiber can be easily broken if the analyst is not careful enough in the work. In those cases, the fiber needs to be replaced and this can introduce batch-to-batch differences in reproducibility. Cleaning steps must also be considered when SPME is used, especially when salt is added to help in the extraction process that can result in crystallization. Also, SPME procedure needs conditioning to the chromatographic system before the first use. Those facts are not necessary when LPME is used. Moreover, to couple SPME to chromatographic system an interface is needed, especially in HPLC case, whereas with LPME usually the extractant is directly injected with a common syringe $[31,35$, $71,73,85]$.

Another main drawback especially for SPME is the procedure cost. Each fiber allows around 50-60 extractions in DI mode and taking into account the elevated cost of one fiber, each analysis can be expensive. In LPME, there is big variety of liquid extractants that present a wide range of prices. Since, the used liquid volume is minimum, a big number of extractions can be made, and therefore the cost per extraction is considerably reduced. Although it can be complicate to use with complex matrices, microextraction liquid techniques are faster, cheaper and simpler than other sorptive extraction techniques.

\section{Conclusions and Perspectives}

This review presents the recent developments in microextraction techniques for the triazole fungicide determination. Solid phase microextraction (SPME) and liquid phase microextraction (LPME) are the most used procedures in microextraction. Both microextraction techniques show a big potential to isolate and preconcentrate triazole compounds not only in water and liquid fruit samples, but also in other complex matrices. After the extraction, the sample can be injected in GC or HPLC instruments equipped with FID, GC, NPD, DAD or MS detectors.

One remarkable characteristic of these microextraction procedures is the tiny volume amount of the used solvents. The great reduction of solvent volumes, mainly the toxic ones, comparing with the volume used in classic extraction procedures make these techniques safer from the environmental point of view.

Although SPME gives good analytical results LPME shows in general better quality data. Moreover, in LPME a wider range of solvents is available allowing more versatility. The dispersive liquid-liquid microextraction allows to increase the contact area and therefore to reduce the extraction time.

The main SPME drawbacks are the fragility of the fiber and the reproducibility. Analysts have to be meticulous in the work trying to avoid the mentioned drawbacks. Respect to the coatings options, the principal supplier can offer about ten different coatings that partially reduce the application spectrum. At the present, one of the most interesting research area is relating to development of new extractant material like molecularly imprinted polymers.

The major development for the future for these microextraction procedures will be focused in the automation. Automation reduces error sources and therefore better results can be obtained. Automatic SPME samplers are actually in the market, but to automatize LPME is more difficult. Some procedures or part of the procedures can be automatized, but can be difficult to automatize every method in a whole.

\section{Acknowledgments}

Authors are grateful to the University of Basque Country (UPV/EHU) for financial support (pre-doctoral fellowship for A. B. and EHU 11/20 project).

\section{References}

1. Scherm H, Christiano RSC, Esker PD, Del Ponte EM, Godoy CV. 2009. Quantitative review of fungicide efficacy trials for managing soybean rust in Brazil. Crop Prot 28(9): 774-782. doi: 10.1016/j. cropro.2009.05.006

2. Zhang Y, Zhang X, Chen C, Zhou M, Wang H. 2010. Effects of fungicides JS399-19, azoxystrobin, tebuconazloe, and carbendazim on the physiological and biochemical indices and grain yield of winter wheat. Pestic Biochem Physiol 98(2): 151-157. doi: 10.1016/j. pestbp.2010.04.007

3. Ekman DR, Keun HC, Eads CD, Furnish CM, Murrell RN, et al. 2006. Metabolomic evaluation of rat liver and testis to characterize the toxicity of triazole fungicides. Metabolomics 2(2): 63-73. doi: 10.1007/ s11306-006-0020-8

4. WolfDC,Allen JW, George MH,Hester SD, Sun G, et al.2006. Toxicity profiles in rats treated with tumorigenic and nontumorigenic triazole conazole fungicides: propiconazole, tridimefon and myclobutanil. Toxicol Pathol 34(7): 895-902. doi: 10.1080/01926230601047808

5. Goetz AK, Ren H, Schmid JE, Blystone CR, Thillainadarajah I, et al. 2007. Disruption of testosterone homeostasis as a mode of action for the reproductive toxicity of triazole fungicides in the male rat. Toxicol Sci 95(1): 227-239. doi: 10.1093/toxsci/kfl124 
6. Taxvig C, Hass U, Axelstad M, Dalgaard M, Boberg J, et al. 2007. Endocrine-disrupting activities in vivo of the fungicides tebuconazole and epoxiconazole. Toxicol Sci 100(2): 464-473. doi: 10.1093/toxsci/ $\mathrm{kfm} 227$

7. Allen JW, Wolf DC, George MH, Hester SD, Sun G, et al. 2006 Toxicity profiles in mice treated with hepatotumorigenic and nonhepatotumorigenic triazole conazole fungicides: propiconazole, triadimefon, and myclobutanil. Toxicol Pathol 34(7): 853-862. doi: 10.1080/01926230601047816

8. Echeverría-Sáenz S, Mena F, Pinnock M, Ruepert C, Solano K, et al. 2012. Environmental hazards of pesticides from pineapple crop production in the Río Jiménez watershed (Caribbean Coast, Costa Rica). Sci Total Environ 440: 106-114. doi: 10.1016/j.scitotenv.2012.07.092

9. Navarro S, Vela N, Pérez G, Navarro G. 2011. Effect of sterol biosynthesis-inhibiting (SBI) fungicides on the fermentation rate and quality of young ale beer. Food Chem 126(2): 623-629. doi: 10.1016/j. foodchem.2010.11.069

10. Tomlin CDS. 2000. The pesticide manual: a world compendium $\left(12^{\text {th }}\right.$ ed). The British Crop Protection Council. Farnham, Surrey, UK.

11. Regulation (EC) No 396/2005 of the European Parliament and of the Council of 23 February 2005 on maximum residue levels of pesticides in or on food and feed of plant and animal origin and amending Council Directive 91/414/EEC. OffJ Eur Union L 70/1-16.

12. European Commission. 2016. EU - pesticides database.

13. Ridgway K, Lalliie SPD, Smith RM. 2007. Sample preparation techniques for the determination of trace residues and contaminants in foods. $J$ Chromatogr A 1153(1-2): 36-53. doi: 10.1016/j. chroma.2007.01.134

14. Gilbert-López B, García-Reyes JF, Molina-Díaz A. 2009. Sample treatment and determination of pesticide residues in fatty vegetable matrices: a review. Talanta 79(2): 109-128. doi: 10.1016/j. talanta.2009.04.022

15. Zhang L, Liu S, Cui X, Pan C, Zhang A, et al. 2012. A review of sample preparation methods for pesticide residue analysis. Cent Eur J Chem 10(3): 900-925. doi: 10.2478/s11532-012-0034-1

16. Buszewski B, Szultka M. 2012. Past, present, and future of solid phase extraction: a review. Crit Rev Anal Chem 42: 198-213. doi: 10.1080/07373937.2011.645413

17. Moreda-Piñeiro J, Moreda-Piñeiro A. 2015. Recent advances in combining microextraction techniques for sample pre-treatment. $\operatorname{Tr} A C$ Trends Anal Chem 71: 265-274. doi: 10.1016/j.trac.2015.02.025

18. Arthur CL, Pawliszyn J. 1990. Solid phase microextraction with thermal desorption using fused silica optical fibers. Anal Chem 62(19): 2145-2148. doi: 10.1021/ac00218a019

19. Pawliszyn J. 1997. Solid phase microextraction. theory and practice ( $1^{\text {st }}$ ed). Wiley-VCH, New York, USA.

20. Peñalver A, Pocurull E, Borrull F, Marcé RM. 1999. Trends in solid-phase microextraction for determining organic pollutants in environmental samples. TrAC Trends Anal Chem 18(8): 557-568. doi: 10.1016/S0165-9936(99)00145-4

21. Pawliszyn J. 2009. Handbook of solid phase microextraction ( $1^{\text {st }}$ ed) Chemical Industry Press, Beijing, China.

22. Abdulra'uf LB, Chai MK, Tan GH. 2012. Applications of solidphase microextraction for the analysis of pesticide residues in fruits and vegetables: a review. J AOAC Int 95(5): 1272-1290. doi: 10.5740/ jaoacint.SGE_Abdulrauf

23. Aulakh JS, Malik AK, Kaur V, Schmitt-Kopplin P. 2005. A review on solid phase microextraction-high performance liquid chromatography (SPME-HPLC) analysis of pesticides. Crit Rev Anal Chem 35(1): 7185. doi: 10.1080/10408340590947952

24. Alpendurada MF. 2000. Solid-phase microextraction: a promising technique for sample preparation in environmental analysis. $J$ Chromatogr A 889(1-2): 3-14. doi: 10.1016/S0021-9673(00)00453-2
25. Spietelun A, Pilarczyk M, Kloskowski A, Namiesnik J. 2010. Current trends in solid-phase microextraction (SPME) fibre coatings. Chem Soc Rev 39(11): 4524. doi: 10.1039/C003335A

26. Lord HL. 2007. Strategies for interfacing solid-phase microextraction with liquid chromatography. $J$ Chromatogr A 1152(1-2): 2-13. doi: 10.1016/j.chroma.2006.11.073

27. Kumar A, Malik AK. 2009. A review on the hyphenation of solid phase microextraction with capillary electrophoresis and mass spectrometry. Crit Rev Anal Chem 39(2): 81-88. doi: 10.1080/15389580802570192

28. Kataoka H, Lord HL, Pawliszyn J. 2000. Applications of solid-phase microextraction in food analysis. J Chromatogr A 880(1-2): 35-62. doi: 10.1016/S0021-9673(00)00309-5

29. Jeannot MA, Cantwell FF. 1996. Solvent microextraction into a single drop. Anal Chem 68(13): 2236-2240. doi: 10.1021/ac960042z

30. Ahmad W, Al-Sibaai AA, Bashammakh AS, Alwael H, El-Shahawi MS. 2015. Recent advances in dispersive liquid-liquid microextraction for pesticide analysis. TrAC Trends Anal Chem 72: 181-192. doi: 10.1016/j.trac.2015.04.022

31. Mohamadi M, Mostafavi A. 2010. A novel solidified floating organic drop microextraction based on ultrasound-dispersion for separation and preconcentration of palladium in aqueous samples. Talanta 81(12): 309-313. doi: 10.1016/j.talanta.2009.12.004

32. Pakade YB, Tewary DK. 2010. Development and applications of singledrop microextraction for pesticide residue analysis: a review. I Sep Sci 33(23-24): 3683-3691. doi: 10.1002/jssc.201000331

33. Viñas P, Campillo N, Andruch V. 2015. Recent achievements in solidified floating organic drop microextraction. TrAC Trends Anal Chem 68: 48-77. doi: 10.1016/j.trac.2015.02.005

34. Ganjali MR, Sobhi HR, Farahani H, Norouzi P, Dinarvand R, et al. 2010. Solid drop based liquid-phase microextraction. J Chromatogr A 1217(16): 2337-2341. doi: 10.1016/j.chroma.2009.11.026

35. Han D, Row K. 2012. Trends in liquid-phase microextraction, and its application to environmental and biological samples. Microchim Acta 176(1): 1-22. doi: 10.1007/s00604-011-0678-0

36. Krylov V, Krylov A, Mosyagin P, Matkivskaya Y. 2011. Liquid-phase microextraction preconcentration of impurities. J Anal Chem 66(4): 331-350. doi: 10.1134/S1061934811040101

37. Abolghasemi MM, Hassani S, Bamorowat M. 2016. Efficient solidphase microextraction of triazole pesticides from natural water samples using a Nafion-loaded trimethylsilane-modified mesoporous silica coating of type SBA-15. Microchim Acta 183(2): 889-895. doi: 10.1007/ s00604-015-1724-0

38. Freitas LA, Vieira AC, Mendonca JA, Costa Figueiredo EC. 2014. Molecularly imprinted fibers with renewable surface for solid-phase microextraction of triazoles from grape juice samples followed by gas chromatography mass spectrometry analysis. Analyst 139(3): 626-632. doi: 10.1039/C3AN01756g

39. Bordagaray A, García-Arrona R, Millán E. 2013. Development and application of a screening method for triazole fungicide determination in liquid and fruit samples using solid-phase microextraction and HPLCDAD. Anal Methods 5(10): 2565-2571. doi: 10.1039/C3AY26433E

40. Souza-Silva EA, Lopez-Avila V, Pawliszyn J. 2013. Fast and robust direct immersion solid phase microextraction coupled with gas chromatography-time-of-flight mass spectrometry method employing a matrix compatible fiber for determination of triazole fungicides in fruits. J Chromatogr A 1313: 139-146. doi: 10.1016/j. chroma.2013.07.071

41. Bordagaray A, García-Arrona R, Millán E. 2011. Optimization of solid-phase microextraction procedure coupled to GC-ECD for triazole fungicides determination in juice samples. Food Anal Methods 4(3): 293-299. doi: 10.1007/s12161-010-9168-y

42. Farajzadeh MA, Djozan D, Nouri N, Bamorowat M, Shalamzari MS. 2010. Coupling stir bar sorptive extraction-dispersive liquidliquid microextraction for preconcentration of triazole pesticides from 
aqueous samples followed by GC-FID and GC-MS determinations. $J$ Sep Sci 33(12): 1816-1828. doi: 10.1002/jssc.201000088

43. Farajzadeh MA, Djozan D, Khorram P. 2011. Development of a new microextraction method based on a dynamic single drop in a narrowbore tube: application in extraction and preconcentration of some organic pollutants in well water and grape juice samples. Talanta $85(2)$ : 1135-1142. doi: 10.1016/j.talanta.2011.05.044

44. Bolzan CM, Caldas SS, Guimarães BS, Primel EG. 2015. Dispersive liquid-liquid microextraction with liquid chromatography-tandem mass spectrometry for the determination of triazine, neonicotinoid, triazole and imidazolinone pesticides in mineral water samples. J Braz Chem Soc 26(9): 1902-1913. doi: 10.5935/0103-5053.20150168

45. Farajzadeh MA, Mogaddam MR, Ghorbanpour H. 2014. Development of a new microextraction method based on elevated temperature dispersive liquid-liquid microextraction for determination of triazole pesticides residues in honey by gas chromatography-nitrogen phosphorus detection. J Chromatogr A 1347: 8-16. doi: 10.1016/j. chroma.2014.04.067

46. Luo M, Liu D, Zhou Z, Wang P. 2013. A new chiral residue analysis method for triazole fungicides in water using dispersive liquid-liquid microextraction (DLLME). Chirality 25(9): 567-574. doi: 10.1002/ chir.22172

47. Farajzadeh MA, Djozan D, Khorram P. 2012. Development of a new dispersive liquid-liquid microextraction method in a narrow-bore tube for preconcentration of triazole pesticides from aqueous samples. Anal Chim Acta 713: 70-78. doi: 10.1016/j.aca.2011.11.030

48. Ye C, Liu Q, Wang Z, Fan J. 2012. Dispersive liquid-liquid microextraction combined with high-performance liquid chromatography-ultraviolet detection for the determination of three triazole derivatives in environmental water samples. Int J Environ Anal Chem 92(10): 1176-1186. doi: 10.1080/03067319.2010.523465

49. Farajzadeh MA, Bahram M,Jafary F, Bamorowat M.2011. Combination of extraction by silylated vessel-dispersive liquid-liquid microextraction as a high-enrichment factor technique: optimization and application in preconcentration of some triazole pesticides from aqueous samples followed by GC-FID determination. Chromatographia 73(3): 393-401. doi: 10.1007/s10337-010-1895-0

50. Farajzadeh MA, Djozan D, Mogaddam MR, Bamorowat M. 2011 Extraction and preconcentration technique for triazole pesticides from cow milk using dispersive liquid-liquid microextraction followed by GC-FID and GC-MS determinations. J Sep Sci 34(11): 1309-1316. doi: $10.1002 /$ jssc. 201000928

51. Wang C, Wu Q, Wu C, Wang Z. 2011. Application of dispersionsolidification liquid-liquid microextraction for the determination of triazole fungicides in environmental water samples by high-performance liquid chromatography. J Hazard Mater 185(1): 71-76. doi: 10.1016/j. jhazmat.2010.08.124

52. Ravelo-Pérez LM, Hernández-Borges J, Asensio-Ramos M, Rodríguez-Delgado MA. 2009. Ionic liquid based dispersive liquidliquid microextraction for the extraction of pesticides from bananas. $J$ Chromatogr A 1216(43): 7336-7345. doi: 10.1016/j.chroma.2009.08.012

53. Wang H, Yang X, Hu L, Gao H, Lu R, et al. 2016. Detection of triazole pesticides in environmental water and juice samples using dispersive liquid-liquid microextraction with solidified sedimentary ionic liquids. New J Chem 40: 4696-4704. doi: 10.1039/C5NJ03376D

54. Xu X, Ye J, Nie J,Li Z, Lee M.2015. A new liquid-liquid microextraction method by ultrasound assisted salting-out for determination of triazole pesticides in water samples coupled by gas chromatographymass spectrometry. Anal Methods 7(3): 1194-1199. doi: 10.1039/ C4AY02448F

55. Bordagaray A, García-Arrona R, Millán E. 2014. Determination of triazole fungicides in liquid samples using ultrasound-assisted emulsification microextraction with solidification of floating organic droplet followed by high-performance liquid chromatography. Food Anal Methods 7(6): 1195-1203. doi: 10.1007/s12161-013-9733-2

56. Li Y, Yang X, Zhang J, Li M, Zhao X, et al. 2014. Ultrasound-assisted emulsification magnetic microextraction: a fast and green method for the determination of triazole fungicides in fruit juice. Anal Methods 6: 8328-8336. doi: 10.1039/C4AY01190B

57. Wang S, Ren L, Xu Y, Liu F. 2011. Application of ultrasoundassisted ionic liquid dispersive liquid-phase microextraction followed high-performance liquid chromatography for the determination of fungicides in red wine. Microchim Acta 173(3): 453-457. doi: 10.1007/ s00604-011-0577-4

58. Farajzadeh MA, Feriduni B, Mogaddam MR. 2015. Determination of triazole pesticide residues in edible oils using air-assisted liquidliquid microextraction followed by gas chromatography with flame ionization detection. J Sep Sci 38(6): 1002-1009. doi: 10.1002/ jssc. 201400818

59. Farajzadeh MA, Feriduni B, Mogaddam MRA. 2014. Extraction and enrichment of triazole and triazine pesticides from honey using air-assisted liquid-liquid microextraction. I Food Sci 79(10): H2140-H2148. doi: 10.1111/1750-3841.12597

60. Farajzadeh MA, Khoshmaram L. 2013. Air-assisted liquid-liquid microextraction-gas chromatography-flame ionisation detection: a fast and simple method for the assessment of triazole pesticides residues in surface water, cucumber, tomato and grape juices samples. Food Chem 141(3): 1881-1887. doi: 10.1016/j.foodchem.2013.05.088

61. Farajzadeh MA, Mogaddam MR, Aghdam AA. 2013. Comparison of air-agitated liquid-liquid microextraction technique and conventional dispersive liquid-liquid micro-extraction for determination of triazole pesticides in aqueous samples by gas chromatography with flame ionization detection. J Chromatogr A 1300: 70-78. doi: 10.1016/j. chroma.2013.02.033

62. Xue J, Li H, Liu F, Jiang W, Hou F. 2016. Vortex-assisted matrix solid-liquid dispersive microextraction for the analysis of triazole fungicides in cotton seed and honeysuckle by gas chromatography. Food Chem 196: 867-876. doi: 10.1016/j.foodchem.2015.09.093

63. Sarafraz-Yazdi A, Assadi H, Ibrahim WAW. 2012. Determination of triazole fungicides using hollow fiber liquid phase microextraction prior to gas chromatography-mass spectrometry analysis. Ind Eng Chem Res 51(7): 3101-3107. doi: 10.1021/ie202856h

64. Wang W, Ma X, Wu Q, Wang C, Zang X, et al. 2012. The use of graphene-based magnetic nanoparticles as adsorbent for the extraction of triazole fungicides from environmental water. J Sep Sci 35(17): 2266-2272. doi: 10.1002/jssc.201200285

65. Tang T, Qian K, Shi T, Wang F, Li J, et al. 2010. Determination of triazole fungicides in environmental water samples by high performance liquid chromatography with cloud point extraction using polyethylene glycol 600 monooleate. Anal Chim Acta 680(1-2): 26-31. doi: 10.1016/j.aca.2010.09.034

66. Pawliszyn J, Pedersen-Bjergaard S. 2006. Analytical microextraction: current status and future trends. J Chromatogr Sci 44(6): 291-307. doi: 10.1093/chromsci/44.6.291

67. Spietelun A, Marcinkowski Ł, de la Guardia M, Namieśnik J. 2013. Recent developments and future trends in solid phase microextraction techniques towards green analytical chemistry. J Chromatogr A 1321: 1-13. doi: 10.1016/j.chroma.2013.10.030

68. Pinto MI, Sontag G, Bernardino RJ, Noronha JP. 2010. Pesticides in water and the performance of the liquid-phase microextraction based techniques. a review. Microchem J 96(2): 225-237. doi: 10.1016/j. microc.2010.06.010

69. Sarafraz-Yazdi A, Amiri A. 2010. Liquid-phase microextraction. TrAC Trends Anal Chem 29(1): 1-14. doi: 10.1016/j.trac.2009.10.003

70. Pena-Pereira F, Lavilla I, Bendicho C. 2010. Liquid-phase microextraction techniques within the framework of green chemistry. TrAC Trends Anal Chem 29(7): 617-628. doi: 10.1016/j. trac.2010.02.016

71. Mahugo-Santana C, Sosa-Ferrera Z, Torres Padrón M, Santana Rodríguez JJ. 2011. Application of new approaches to liquid-phase microextraction for the determination of emerging pollutants. $\operatorname{Tr} A C$ 
Trends Anal Chem 30(5): 731-748. doi: 10.1016/j.trac.2011.01.011

72. Dehghani Mohammad Abadi M, Ashraf N, Chamsaz M, Shemiran F. 2012. An overview of liquid phase microextraction approaches combined with UV-Vis spectrophotometry. Talanta 99: 1-12. doi: 10.1016/j.talanta.2012.05.027

73. Spietelun A, Marcinkowski Ł, de la Guardia M, Namieśnik J. 2014. Green aspects, developments and perspectives of liquid phase microextraction techniques. Talanta 119: 34-45. doi: 10.1016/j. talanta.2013.10.050

74. Andrašcíková M, Matisová E, Hrouzková S. 2015. Liquid phase microextraction techniques as a sample preparation step for analysis of pesticide residues in food. Sep Purif Rev 44(1): 1-18. doi: 10.1080/15422119.2013.872125

75. Kokosa JM. 2015. Recent trends in using single-drop microextraction and related techniques in green analytical methods. TrAC Trends Anal Chem 71: 194-204. doi: 10.1016/j.trac.2015.04.019

76. Regueiro J, Llompart M, Garcia-Jares C, Garcia-Monteagudo JC, Cela R. 2008. Ultrasound-assisted emulsification-microextraction of emergent contaminants and pesticides in environmental waters. $J$ Chromatogr A 1190(1-2): 27-38. doi: 10.1016/j.chroma.2008.02.091

77. Wei S, Leong M, Li Y, Huang S. 2011. Development of liquid phase microextraction based on manual shaking and ultrasound-assisted emulsification method for analysis of organochlorine pesticides in aqueous samples. J Chromatogr A 1218(51): 9142-9148. doi: 10.1016/j. chroma.2011.10.084

78. Cortada C, Vidal L, Canals A. 2011. Determination of geosmin and 2-methylisoborneol in water and wine samples by ultrasoundassisted dispersive liquid-liquid microextraction coupled to gas chromatography-mass spectrometry. J Chromatogr A 1218(1): 17-22. doi: 10.1016/j.chroma.2010.11.007

79. Yan H, Wang H, Qin X, Liu B, Du J. 2011. Ultrasound-assisted dispersive liquid-liquid microextraction for determination of fluoroquinolones in pharmaceutical wastewater. J Pharm Biomed Anal 54(1): 53-57. doi: 10.1016/j.jpba.2010.08.007

80. Cheng J, Xia Y, Zhou Y, Guo F, Chen G. 2011. Application of an ultrasound-assisted surfactant-enhanced emulsification microextraction method for the analysis of diethofencarb and pyrimethanil fungicides in water and fruit juice samples. Anal Chim Acta 701(1): 86-91. doi: 10.1016/j.aca.2011.04.058

81. Cheng J, Matsadiq G, Liu L, Zhou Y, Chen G. 2011. Development of a novel ultrasound-assisted surfactant-enhanced emulsification microextraction method and its application to the analysis of eleven polycyclic aromatic hydrocarbons at trace levels in water. J Chromatogr A 1218(18): 2476-2482. doi: 10.1016/j.chroma.2011.02.049

82. ZhangJ,GaoH,PengB,LiY,LiS,etal.2012.Simultaneous determination of four synthesized metabolites of mequindox in urine samples using ultrasound-assisted dispersive liquid-liquid microextraction combined with high-performance liquid chromatography. Talanta 88: 330-337. doi: 10.1016/j.talanta.2011.10.049

83. Xia Y, Zhi X, Wang X, Chen M, Chen J. 2012. Ultrasound-enhanced surfactant-assisted dispersive liquid-liquid microextraction and highperformance liquid chromatography for determination of ketoconazole and econazole nitrate in human blood. Anal Bioanal Chem 402: 12411247. doi: 10.1007/s00216-011-5508-z

84. You X, Wang S, Liu F, Shi K. 2013. Ultrasound-assisted surfactantenhanced emulsification microextraction based on the solidification of a floating organic droplet used for the simultaneous determination of six fungicide residues in juices and red wine. J Chromatogr A 1300: 64-69. doi: 10.1016/j.chroma.2013.02.038

85. Saraji M, Boroujeni MK. 2014. Recent developments in dispersive liquid-liquid microextraction. Anal Bioanal Chem 406(8): 2027-2066. doi: 10.1007/s00216-013-7467-z 